\title{
Intestinal stomas: A clinical study in a Teaching Hospital, our experience Karki OB ID $ه$
}

Om Bahadur Karki, Department of Surgery, Manipal College of Medical Sciences, Pokhara, Nepal

\begin{abstract}
Background: An intestinal stoma is an opening of the intestine on anterior abdominal wall made with an intention of either decompression of an obstructed colon or diversion of stool. Intestinal stomas may be temporary or permanent, depending on their role.

Objectives: The objective of this study was to determine the common indications and types of intestinal stomas, and outcomes of patients operated at Manipal Teaching Hospital, Pokhara, Nepal.

Methodology: A retrospective cross-sectional study was conducted in 105 patients of intestinal stomas from February 2017 to March 2020 in a teaching hospital after approval from institutional review committee. Data were derived from medical records of patients and operation logbooks with the consecutive sampling method. Data were analyzed with the help of the Statistical Package for Social Sciences (SPSS) version 20 and p value $<0.05$ was considered significant.

Results: Total of 105 patients with intestinal stomas was included for the study of which $82.9 \%$ ( $n=63$ ) were emergency operations and $17.1 \%(n=13)$ were elective. There were $46(43.80 \%)$ cases of ileostomy, $9(8.5 \%)$ jejunostomy and $50(47.6 \%)$ colostomy patients. Major indications of stoma formation were trauma $33.3 \%(n=35)$ and intestinal obstruction $22.8 \%$ $(n=24)$. Complications were observed in $39(37.14 \%)$ of the patients, with wound infection $11.8 \%(n=9)$ and peristomal dermatitis $11.8 \%(n=9)$ for ostomates being the commonest. Higher complications were seen with ileostomy as compared to colostomy $(p=0.02)$ and loop ileostomy still higher than end ileostomy $(p=0.00)$.

Conclusion: Common indications for intestinal stomas were abdominal trauma, enteric perforation, intestinal obstruction and colorectal carcinoma. Main complications included local skin problems, wound infection and retraction.
\end{abstract}

Key words: Colostomy; lleostomy; Surgical stomas; Wound infection.

\section{INTRODUCTION}

toma or ostomy is an opening on anterior abdominal $\checkmark$ wall made surgically in order to divert the flow of feces or urine ${ }^{1}$. Though any segment of bowel can be

\section{Access this article online}

Website: www.jkmc.com.np

DOI: https://doi.org/10.3126/jkmc.v9i1.33543

\section{HOW TO CITE}

Karki OB. Intestinal stomas: A clinical study in a Teaching Hospital, our experience. J Kathmandu Med Coll. 2020;9(1):37-42.

\section{Address for correspondence \\ Dr. Om Bahadur Karki \\ Department of Surgery \\ Manipal College of Medical Sciences, \\ Pokhara, Nepal \\ E-mail:karkiom10@gmail.com}

Copyright ๑ 2020 Journal of Kathmandu Medical College (JKMC)

ISSN: 2019-1785 (Print), 2091-1793 (Online)

(i) (8) This work is licensed under a Creative Commons Attribution-Non Commercial 4.0 International License. exteriorized to form a stoma, commonly performed procedures include either colon and ileum as a conduit ${ }^{2}$. Stoma may be temporary or permanent; depending on their role. Based upon the technique it can be loop, double barrel or end stoma ${ }^{3}$.

Unlike adults, stoma formation in children mostly is a temporary surgery for management of congenital malformations ${ }^{4}$. In adults, conditions such as inflammatory bowel diseases, obstruction, perforation, trauma, malignancies etc. require stoma formation ${ }^{4-5}$. Although a life-saving procedure, formation and reversal of stomas are associated with complications ${ }^{6-7}$. Moreover, some patients also suffer from social stigma including domestic and psychological distress ${ }^{8}$.

The aim of our study was therefore to evaluate our own experience of various types of intestinal stomas and complications related to them. 


\section{METHODOLOGY}

This was a retrospective study done in the Department of Surgery, Manipal College of Medical Sciences, Pokhara, Nepal from February 2017 to March 2020. All patients with intestinal stomas operated in our center during that period were included in the study.

The sample size was calculated by standard formula i.e. Sample $(n)=z^{2} p q / d^{2}$ where, $n=$ sample size, $p=$ prevalence, $q=1-p, d=$ precision in proportion of one (i.e. $5 \%=0.05), z=1.96$ at $95 \%$ confidence interval ${ }^{9}$. On the basis of the prevalence of intestinal stomas derived from previous study ${ }^{10}, p=0.0487$. After the calculation, $n=$ $1.96^{2} \times(0.0487 \times 0.95) / 0.0025=71$. However, we included 105 patients in the study, of which 76 patients were for stoma formation. Consecutive sampling method was used to collect samples.

Operation theater logbook and patient case records were used as sources of data. Operative findings, procedure done, immediate and late complications as well as details about stoma, appliances, complications and its management were recorded. The cases studied were categorized according to

- $\quad$ Age and sex of patient undergoing the procedure.

- The primary pathology or indication for stoma formation.

- The setting in which the procedure was performed i.e. emergency or elective.

- Type of stoma and nature of stoma.

- Complications

Patients with enterocutaneous fistulas, patients with urinary diversion procedures which involve creation of intestinal stomas, and patients with biochemical complications were excluded from the study.

Statistical package for Social Science evaluation version 20 (IBM-SPSS20 Inc; Chicago, IL, USA) was used for analysis. Quantitative variables are expressed as mean (standard deviation). Qualitative variables are presented as numbers (percentage) and evaluated using Fisher exact test. The associations of different variables related to complications of stoma were tested for significance in chi square analysis. Considering a confidence level of $95 \%$, a $p$-value of $<0.05$ was considered significant in all statistical comparison. Approval of the institutional ethical committee was taken prior to conducting the study.

\section{RESULTS}

In the present study there were 105 patients of which, 76 patients had intestinal stoma formation and 29 patients for stoma reversal. Males 61(58.1\%) outnumbered females $44(41.9 \%)$ by ratio of $1.38: 1$. The mean age of the patients was $42.42 \pm 23.73$ years. Of the stomas made, $13(17.1 \%)$ were scheduled while 63(82.9\%) had to be made in emergency while all stoma reversal was planned. In our study, the median duration for reversal of stoma was two months from the time of stoma formation. The indications of intestinal stoma formation were as in table 1.

There were 46 (43.80\%) cases of ileostomy, 9(8.5\%) jejunostomy and $50(47.6 \%)$ colostomy during the study period. The types of stomas are given in table 2 .

The complications encountered were distributed as the ones observed in the patients undergone stoma formation and stoma closure. Complications were observed in 39 (37.14\%) of the patients. Surgical site infection $11.8 \%(n=9)$ and peristomal dermatitis $11.8 \%$ $(n=9)$ were common complications for ostomates. (Table 3)

We have reported higher complications with ileostomy as compared to colostomy $(p=0.02)$ and loop ileostomy have still higher than end ileostomy $(p=<0.001)$. Also patients with high body mass index (BMI) encountered more complications $(p=<0.001)$. (Table 4)

Higher grades of American Society of Anesthesiologist (ASA) score $(p=0.00)$, obesity $(p=0.03)$ and delayed closure of stoma $(p=0.00)$ were associated with high complication rate for stoma reversal in our study. (Table 5)

Table 1: Indications of stoma formation.

\begin{tabular}{lcc|}
\hline Indication & Number & Percentage \\
\hline Anastomotic dehisence & 8 & 7.6 \\
\hline Congenital anomalies & 4 & 3.8 \\
\hline Diverticular perforation & 1 & 1.0 \\
\hline Enteric fever (typhoid) & 3 & 2.9 \\
\hline Fournier's gangrene & 2 & 1.9 \\
\hline Inflammatory bowel disease & 4 & 3.8 \\
\hline Malignancy & 20 & 19.0 \\
\hline Obstruction & 24 & 22.8 \\
\hline Trauma & 35 & 33.3 \\
\hline Tuberculosis & 4 & 3.8 \\
\hline
\end{tabular}


Table 2: Types of intestinal stomas

\begin{tabular}{lcc|}
\hline Stoma type & Number & Percentage \\
\hline Loop ileostomy & 36 & 34.28 \\
\hline Loop jejunostomy & 9 & 8.5 \\
Double barrel ileostomy & 6 & 5.7 \\
End ileostomy & 4 & 3.8 \\
Loop colostomy & 30 & 28.57 \\
\hline Double barrel colostomy & 4 & 3.8 \\
\hline Hartman's procedure & 7 & 6.6 \\
\hline End colostomy (permanent) & 9 & 8.5 \\
\hline
\end{tabular}

Table 3: Complications related with intestinal stoma

\begin{tabular}{|c|c|c|}
\hline Complications & Number & Percentage \\
\hline \multicolumn{3}{|c|}{ Related to stoma formation $(n=76)$} \\
\hline Bleeding & 2 & 2.6 \\
\hline Necrosis & 1 & 1.3 \\
\hline Parastomal hernia & 3 & 3.9 \\
\hline Protusion & 1 & 1.3 \\
\hline Peristomal dermatitis & 9 & 11.8 \\
\hline Retraction & 4 & 5.3 \\
\hline Surgical site infection & 9 & 11.8 \\
\hline Stenosis & 2 & 2.6 \\
\hline \multicolumn{3}{|c|}{ Related to stoma reversal $(n=29)$} \\
\hline Anastomotic leakage & 1 & 3.44 \\
\hline Paralytic ileus & 3 & 10.3 \\
\hline Surgical site infection & 2 & 6.9 \\
\hline Incisional hernia & 2 & 6.9 \\
\hline
\end{tabular}

Table 4: Predictors of stoma related complications in patients for stoma formation

\begin{tabular}{|c|c|c|c|}
\hline \multirow{2}{*}{ Variable } & \multicolumn{2}{|c|}{ Complications } & \multirow{2}{*}{ p-value } \\
\hline & Absent & Present & \\
\hline \multicolumn{4}{|l|}{ Age $^{*}$} \\
\hline$<50$ years & 24 & 18 & \multirow[t]{2}{*}{0.68} \\
\hline$>50$ years & 21 & 13 & \\
\hline \multicolumn{4}{|l|}{ Sex } \\
\hline Male & 26 & 18 & \multirow[t]{2}{*}{0.98} \\
\hline Female & 19 & 13 & \\
\hline \multicolumn{4}{|l|}{ Nature } \\
\hline Emergency & 34 & 29 & \multirow[t]{2}{*}{0.04} \\
\hline Elective & 11 & 2 & \\
\hline \multicolumn{4}{|l|}{ Comorbidity } \\
\hline Absent & 30 & 14 & \multirow[t]{2}{*}{0.06} \\
\hline Present & 15 & 17 & \\
\hline \multicolumn{4}{|l|}{ Site } \\
\hline Ileostomy & 26 & 10 & \multirow[t]{2}{*}{0.02} \\
\hline Colostomy & 19 & 21 & \\
\hline \multicolumn{4}{|l|}{ Type } \\
\hline Loop & 29 & 22 & \multirow{3}{*}{$<0.001$} \\
\hline End & 14 & 6 & \\
\hline Double barrel & 2 & 3 & \\
\hline \multicolumn{4}{|c|}{ Obesity(BMI>25) † } \\
\hline Absent & 36 & 13 & \multirow[t]{2}{*}{$<0.001$} \\
\hline Present & 9 & 18 & \\
\hline
\end{tabular}

*Median age 50 years; ${ }^{\dagger}$ Body mass index (BMI). 
Table 5: Predictors of stoma related complications in patients for stoma reversal

\begin{tabular}{|c|c|c|c|}
\hline Variable & Complications Absent & Present & P value \\
\hline \multicolumn{4}{|l|}{ Age* $^{*}$} \\
\hline$<29$ years & 13 & 2 & 0.10 \\
\hline$>29$ years & 8 & 6 & \\
\hline \multicolumn{4}{|l|}{ Sex } \\
\hline Male & 11 & 6 & 0.40 \\
\hline Female & 10 & 2 & \\
\hline \multicolumn{4}{|l|}{ Obesity (BMI>25) † } \\
\hline Absent & 15 & 2 & 0.03 \\
\hline Present & 6 & 6 & \\
\hline \multicolumn{4}{|l|}{ ASA score $\ddagger$} \\
\hline $\mathrm{I}, \mathrm{II}$ & 20 & 2 & 0.00 \\
\hline III,IV,V & 1 & 6 & \\
\hline \multicolumn{4}{|l|}{ Timing of stoma reversal } \\
\hline 2-6 months & 19 & 1 & 0.00 \\
\hline$>6$ months & 2 & 7 & \\
\hline \multicolumn{4}{|l|}{ Site } \\
\hline Small bowel (ileostomy) & 13 & 3 & 0.40 \\
\hline Large bowel (colostomy) & 8 & 5 & \\
\hline
\end{tabular}

*Median age 29 years; ${ }^{\dagger}$ Body mass index(BMI); ${ }^{\ddagger}$ American Society of Anesthesiologist.

\section{DISCUSSION}

Despite the advances made in medicine, intestinal ostomies are an indispensable aspect of clinical practice especially during emergency laparotomies ${ }^{11}$. The term "ostomy" comes from the Greek word "stoma" and means "mouth"12. Littre of Paris was the first to do a ventral colostomy in 1710 for a baby with imperforate anus $^{13}$. Majority $(82.9 \%)$ of stomas were made during emergency and $13(17.1 \%)$ were planned. Similar is the trend worldwide as shown by other studies ${ }^{1,6,14}$. The most common type of intestinal stoma made in our study was loop ileostomy (42.85\%) followed by loop colostomy $(28.57 \%)$ with most of them being formed in males (58.1\%). Similarly, in a study by Ahmad Z et al. loop ileostomy was the most common stoma formed (64\%) followed by loop colostomy $(11 \%)^{1}$. Ileostomy accounted for $87 \%$ stomas in another study by Dincer $\mathrm{M}$ et al. followed by colostomy $(13 \%)^{14}$. Loop ileostomy is preferred because it is associated with fewer rates of complications (in its construction and closure) ${ }^{15}$.

Common indications of stoma formation in our study were enteric perforation secondary to abdominal trauma in 35 cases (33.3\%) followed by intestinal obstruction in 24 cases $(22.8 \%)$ and malignancy in 20 cases (19.0\%). Indications of stoma formation by Ahmad Z et al. were enteric perforation in 38 cases (38\%) followed by Koch's abdomen in 18 cases (18\%) and carcinoma rectum in 11 cases $(11 \%)^{1}$. Hussain $S$ et al. reported indication of colostomies as penetrating injury (50.87\%) followed by obstruction (33.3\%)and for ileostomy formation was enteric perforation (55.10\%) followed by intestinal tuberculosis $(20.40 \%)^{11}$. While in a study by Osinowo et al. anastomotic dehiscence (15.3\%) was commonest indication for de-functioning stomas and obstruction due to colorectal carcinoma $(21.2 \%)$ as commonest indication for decompression stomas ${ }^{16}$. Congenital anomalies accounted for only a few cases in our study, may be due to early referral of such cases to pediatric surgeons unless a life threatening emergency.

Despite a great number of surgeries, complications are almost inevitable. Stoma formation results in local, systemic and psychological complications ${ }^{7,12}$. Various studies have reported stoma complication rates of $21 \%$ to $70 \%{ }^{17}$.Emergency stomas are shown to have a higher complication rate ${ }^{18,19}$. This was also true in our study which showed a higher rate of complications in the emergency cohort. Complication rate in our study was $37.14 \%$ with surgical site infection (11.8\%), peristomal dermatitis (11.8\%), stoma retraction (5.3\%) and parastomal hernia (3.9\%) as common complications for ostomates and ileus (10.3\%) and wound infection (6.9\%) in patients who had undergone stoma closure. Patients with difficult to fit stomas are at greater risk for developing skin complications and are often encountered in patients with other stoma complications like poor sitting, retraction, prolapse and parastomal hernia ${ }^{7}$. In a study by Ahmad et 
al. $87 \%$ cases developed some sort of complication and reported peristomal skin irritation and erythema (36\%) followed by laparotomy wound infection (13.4\%) and peristomal skin infection, abscess formation and fistula formation $(8.1 \%)^{1}$. Parastomal hernia $(7.5 \%)$ was the commonest complication for all colostomies in study by Harris et al. ${ }^{19}$. Massenga et al. in a study in Tanzania had stoma prolapse as the commonest complication (41.9\%), surgical site infection $16.5 \%$, followed by stoma stenosis at $11.6 \%$.

There are many factors suggested to predispose to stoma complications like high body mass index (BMI), emergency surgery, inflammatory bowel diseases, surgical technique, use of immunosuppressant drugs, old age, and surgeons' experience ${ }^{1,5}$. In the present study also we have reported higher complications with ileostomy as compared to colostomy $(p=0.02)$ and even loop ileostomy have still higher than end ileostomy $(p=0.00)$. Patients who had to undergo stoma formation as emergency procedure had higher complication rate $(p=0.04)$ than in those patients where it was planned. Also patients with high BMl encountered more complications $(p=0.00)$. In a study by Massenga et al. the overall complications rate was significantly higher in stomas performed on emergency basis than that performed electively $(p=0.01)$, in stomas performed by junior doctors than in those performed by senior doctors, $(8.8 \%),(p=0.03)^{5}$. Higher grades of American Society of Anesthesiologist (ASA) score $(p=0.00)$, obesity $(p=0.03)$ and delayed closure of stoma $(p=0.00)$ were associated with high complication rate during stoma closure in our study. Delayed closure of stoma (stoma reversal after six months of formation) was performed in nine patients in our study. Inadequate counseling to patients or patient

\section{REFERENCES}

1. Ahmad Z, Sharma A, Saxena P, Choudhary A, Ahmed M. A clinical study of intestinal stomas: its indications and complications. Int J Res Med Sci 2013;1:536-40. DOI: 10.5455/2320-6012.ijrms20131140. [FullText]

2. Ahmad QA, Saeed MK, Muneera MJ, Ahmad MS, Khalid K. Indications and complications of intestinal stomas- a tertiary care hospital experience. Biomedica. 2010;26:144-7. [FullText]

3. Bhutra S, Singh A, Darwal R, Jain P, Kala V. A clinicoobservational study of intestinal stoma and their complications. IntSurg J 2019;6:691-5. [FullText]

4. Bode CO, Gbobo LI. Childhood colostomy and its complications in Lagos. East and Central Afr J Surg. 2001:25-9. [FullText] parties during the time of discharge, financial and family related were main reasons for late follow up of patients. Complication rate following stoma closure was found to be significantly higher in stoma closed by junior doctors $(\mathrm{OR}=5.23 ; 95 \% \mathrm{Cl}=2.18-9.86 ; \mathrm{p}=0.00)$ and in stomas closed intraperitoneally $(\mathrm{OR}=6.22,95 \% \mathrm{Cl}=2.11-8.92$; $\mathrm{p}=0.012$ ) by Massenga et $\mathrm{al}^{5}$.

Stoma related complications can be reduced significantly by involvement of a stoma therapist or specialized nurses during perioperative assessment and immediate care of such patients. Whether temporary or permanent, proper peri-operative care and education is essential for acclimation to life with a stoma ${ }^{20}$.

Our study represents the findings of a single institution and the patients were not followed up properly so the findings must thus be interpreted within the context of its limitations. Similarly, surgical management was not based on definite protocol but were usual clinical practices.

\section{CONCLUSION}

Creation of an intestinal stoma is a common procedure in surgical practice. Common indications for intestinal stomas were abdominal trauma, enteric perforation, intestinal obstruction and anastomosis dehiscence. Main complications included local skin problems, wound infection and retraction. The association between stoma complications with the site, type and the setting of stoma is notable and warrants further exploration in subsequent studies.

\section{Conflict of interest: None Source(s) of support: None}

5. Massenga A, Chibwae A, Nuri AA, et al. Indications for and complications of intestinal stomas in the children and adults at a tertiary care hospital in a resource-limited setting: a Tanzanian experience. BMC Gastroenterology. 2019 Aug;19(1):157. DOI: 10.1186/s12876-019-1070-5.[FullText]

6. Krishnaswamy J, Kumar S, Mukesh K, Rahman K. A clinical study of intestinal stomas in emergency laparotomy: its complications. IntSurg J 2018;5:2736.[FullText]

7. Kwiatt M, Kawata M. Avoidance and management of stomal complications. Clin Colon Rectal Surg. 2013;26(2):112-21. doi: 10.1055/s-00331348050.[PubMed]

8. Engida A, Ayelign T, Mahteme B, Aida T, Abreham B. Types and Indications of Colostomy and 
Determinants of Outcomes of Patinets After Surgery. Ethiop J Health Sci.2016 Mar; 26(2): 117120. [PubMed]

9. Naing L, Winn T, Rusli BN. Practical issues in calculating the sample size for prevalence studies. Archives of Orofacial Sciences. 2006;1:9-14. [Google Scholar]

10. Latıf A, Shabbır F, Hameed K. Prevalence of intestinal stoma formation in the management of abdominal surgery in Emergency Department of Allamalqbal Memorial Teaching Hospital. P J M H S JUN 2016;10:498-502.[FullText]

11. Hussain S, Aslam V, Khan SM, Jan WA. Ileostomies and colostomies; common reasons and complications of construction: one year study. Professional Med J 2015;22(11):1499-1503. [FullText]

12. Ambe PC, Kurz NR, Nitschke C, Odeh SF, Möslein G, Zirngibl H. Intestinal Ostomy. Dtsch Arztebl Int. 2018;115(11):182-187. doi:10.3238/ arztebl.2018.0182. [PubMed] .

13. Khalid AM, Irshad W. Surgical history of intestinal $\begin{array}{lll}\text { obstruction. } \quad \text { Specialist } 1991 ; 8 & \text { (1):55-60. }\end{array}$ [GoogleScholar]

14. Dincer M, Çıtlak G. Indications and Complications of Stoma Formations in Emergency Surgery. ijirms [Internet]. 2019Feb.24;4(02):139 to 142. [FullText]
15. Pal N, Poonam, Jangra A, Mishra V. Analysis of complications and management of abdominal stoma. IntSurg J 2019;6:2828-31. [FullText]

16. Osinowo AO, Balogun OS, Olajide TO, Lawal OA, Adesanya AA. An appraisal of intestinal stomas at a tertiary hospital in South Western, Nigeria. J ClinSci2018;15:156-61. [FullText]

17. Qureshi A, Cunningham J, Hemandas A. Emergency stomas; should non-colorectal surgeons be doing it? GastroenterolHepatol Bed Bench. 2018;11(4):306-312. [PubMed]

18. Constantinides VA, Heriot A, Remzi F, Darzi A, Senapati A, Fazio VW, et al. Operative strategies for diverticular peritonitis: a decision analysis between primary resection and anastomosis versus Hartmann's procedures. Ann Surg. 2007;245:94103. [PubMed]

19. Harris D A, Egbeare D, Jones S, Benjamin $H$, Woodward A, Foster M E. Complications and mortality following stoma formation. Ann R Collsurg Engl. 2005;87(6):427-431. [PubMed]

20. Steinhagen E, Colwell J, Cannon LM. Intestinal Stomas-Postoperative Stoma Care and Peristomal Skin Complications. Clin Colon Rectal Surg. 2017;30(3):184-192. doi:10.1055/s-0037-1598159. [PubMed] 